\title{
Integration of schistosomiasis control activities within the primary health care system: a critical review
}

\author{
Paul Bizimana ${ }^{1,2,3,4^{*}}$, Giuseppina Ortu ${ }^{5}$, Jean-Pierre Van Geertruyden ${ }^{1}$, Frédéric Nsabiyumva ${ }^{6}$, \\ Audace Nkeshimana ${ }^{2,4}$, Elvis Muhimpundu ${ }^{7}$ and Katja Polman ${ }^{8}$
}

\begin{abstract}
Background: Schistosomiasis is a chronic disease linked to poverty and is widely endemic, particularly in sub-Saharan Africa. For decades, the World Health Organization has called for a larger role of the primary health care system in schistosomiasis control, and its integration within the routine activities of primary health care facilities. Here, we reviewed existing studies on the integration of schistosomiasis control measures within the primary health care system, more precisely at the health centre, and we analysed their outcomes.
\end{abstract}

Methods: An online search of studies published via PubMed and Embase databases was carried out until December 2017. Keywords were used to identify articles related to the integration of schistosomiasis control within the primary health care system, especially at the health centre level. Studies on integration of the following control measures were included: diagnosis and treatment, supplemented or not with (i) health education; (ii) snail control; and (iii) clean water supply and sanitation. A qualitative review was undertaken. To conclude on the effectiveness of an intervention, intermediate outcomes (knowledge, attitude and practice, coverage, access to health care) and distal outcomes (prevalence, incidence, mortality) were considered, and pre/post-intervention results were compared.

Results: Of 569 records found, 11 met the inclusion criteria. Studies were classified in three groups, according to the control measures they included. Integration of diagnosis and treatment, and health education in the first group resulted in an improvement of knowledge level of care providers, access to health care and health care seeking behaviour of the community. However, no positive effect was observed on the knowledge level of symptoms and modes of transmission at the community level. Most studies in the second group (with snail control as additional measure) and the third group (with clean water supply and sanitation as additional measure) showed a positive effect on schistosomiasis prevalence and incidence post-intervention, independent of the additional control measures implemented.

Conclusions: The results of this review suggest a positive impact of integration of schistosomiasis control within the primary health care system. However, more robust studies are needed, especially in resource-limited regions, for conclusive evidence on the effectiveness and the sustainability of this strategy.

Keywords: Control measures, Health centre, Integration, Primary health care system, Review, Schistosomiasis

\footnotetext{
*Correspondence: pbizimana2010@gmail.com; bizap2006@yahoo.fr

2 Département des Sciences de la Santé Publique, Direction de la

Formation, Institut National de Santé Publique, Bujumbura, Burundi

Full list of author information is available at the end of the article
} 


\section{Background}

Schistosomiasis is a parasitic disease acquired through contact with contaminated water, with debilitating and chronic complications [1]. Sub-Saharan Africa is the most affected with more than $90 \%$ of the total burden [2] Estimations indicate that 207 million people are infected [2, 3] and more than 800 million are at risk [3]. In addition, schistosomiasis is responsible for an annual loss of 4.5 million disability-adjusted life years (DALYs) [4, 5] and 200,000 deaths every year [6]. School-age children are the most vulnerable group, with severe consequences for physical and cognitive development $[7,8]$.

For several decades, schistosomiasis prevention and control has been essentially based on vertical programmes organised and coordinated at the national level, with the support of donor organisations $[9,10]$. Within these programmes, mass drug administration (MDA) campaigns delivering praziquantel (PZQ) to populations at risk, especially school-age children [11], have been organised annually or biannually. They have not been integrated within the health care structures but run as interventions in parallel with the routine prevention and control activities performed by the primary health care (PHC) structures [12].

In 1993, the World Health Organization (WHO) called for a larger role of the PHC system in schistosomiasis control [13], and its integration within the routine activities of PHC facilities. The components of this integrated control were defined as (i) health education, (ii) diagnosis and treatment $(\mathrm{D} / \mathrm{T})$, (iii) promotion of clean water supply, (iv) sanitation and (v) control of snails [13], with an emphasis on D/T [13]. This 1993 WHO strategy on integrating schistosomiasis in the PHC system, was reconsidered by the WHO in 2004 [14], and by others in 2010 [15, 16]. Recently in 2017, disease surveillance was added by the WHO [17]. The need to integrate these control measures within the PHC system has also been proposed as a response to the global call for schistosomiasis elimination [17]. Although successes have been reported with MDA [18-20], there is also increasing evidence that MDA alone will not be sufficient for achieving disease elimination [18-20].

So far, only a few studies have been performed on the integration of schistosomiasis control measures within the PHC system, more precisely at the health centre $(\mathrm{HC})$ level. In this article, we review the existing studies and analyse the outcomes.

\section{Methods}

\section{Search strategy and selection criteria}

This review was carried out to identify studies on the implementation of schistosomiasis control in the PHC system, more precisely at the $\mathrm{HC}$ level, published up to
December 2017 and available online, and where intermediate and/or distal outcomes [21] were available.

We performed computer-aided searches of the PubMed/Medline and Embase electronic online databases. Keywords used in PubMed/Medline were: (((integration OR control)) AND (schistosomiasis)) AND ("health centre" OR "Primary health care" OR PHC), while those used in Embase were: ((schisto* AND (integrat* OR control)) AND ((Health centre) OR (Primary health care) OR PHC). Only articles written in English or French were considered. In addition, bibliographies of published studies were screened to find additional sources of data.

Subsequently, the title, abstract and full text were screened to identify articles that fulfil the inclusion criteria. Duplicates were excluded. For the title, only articles that contained "schisto" were selected. The abstracts were screened, and only those describing an intervention were retained. For these studies, full papers were retrieved and further screened. Only studies including $\mathrm{D} / \mathrm{T}$ at least, or supplemented with one or more of the following schistosomiasis control measures: (i) health education, (ii) snail control, and (iii) clean water supply and sanitation [13], in line with the 1993 WHO schistosomiasis control integration strategy [13], as inclusion criteria, were selected. The flow diagram of the literature search strategy is shown in Fig. 1.

From studies fulfilling the inclusion criteria, the following data were recorded: names of first author and year of publication; setting and duration of the intervention; Schistosoma species; control measures; population targeted; results pre/post-intervention; classification group; intervention effect.

\section{Assessment of the study outcomes}

Studies were classified in groups, according to the control measures they included. Group one: studies that reported on $\mathrm{D} / \mathrm{T}$ and health education. Group two: studies that reported on $\mathrm{D} / \mathrm{T}$, health education and snail control. Group three: studies that reported on D/T, health education, snail control, and clean water supply and sanitation. To conclude on the effectiveness of an intervention, different outcomes were considered and pre/post-intervention results were compared.

Two categories of outcomes were assessed: intermediate outcomes and distal outcomes [21-23]. The following intermediate outcomes were considered: (i) knowledge, attitude and practice (KAP) related to schistosomiasis of care providers (staff in charge of consultations and referrals, as a result of training) or targeted populations (as a result of health education); (ii) coverage (of $\mathrm{D} / \mathrm{T}$ ) and (iii) access (i.e. availability and financial accessibility) to health care. Distal outcomes were prevalence, incidence and mortality, due to 

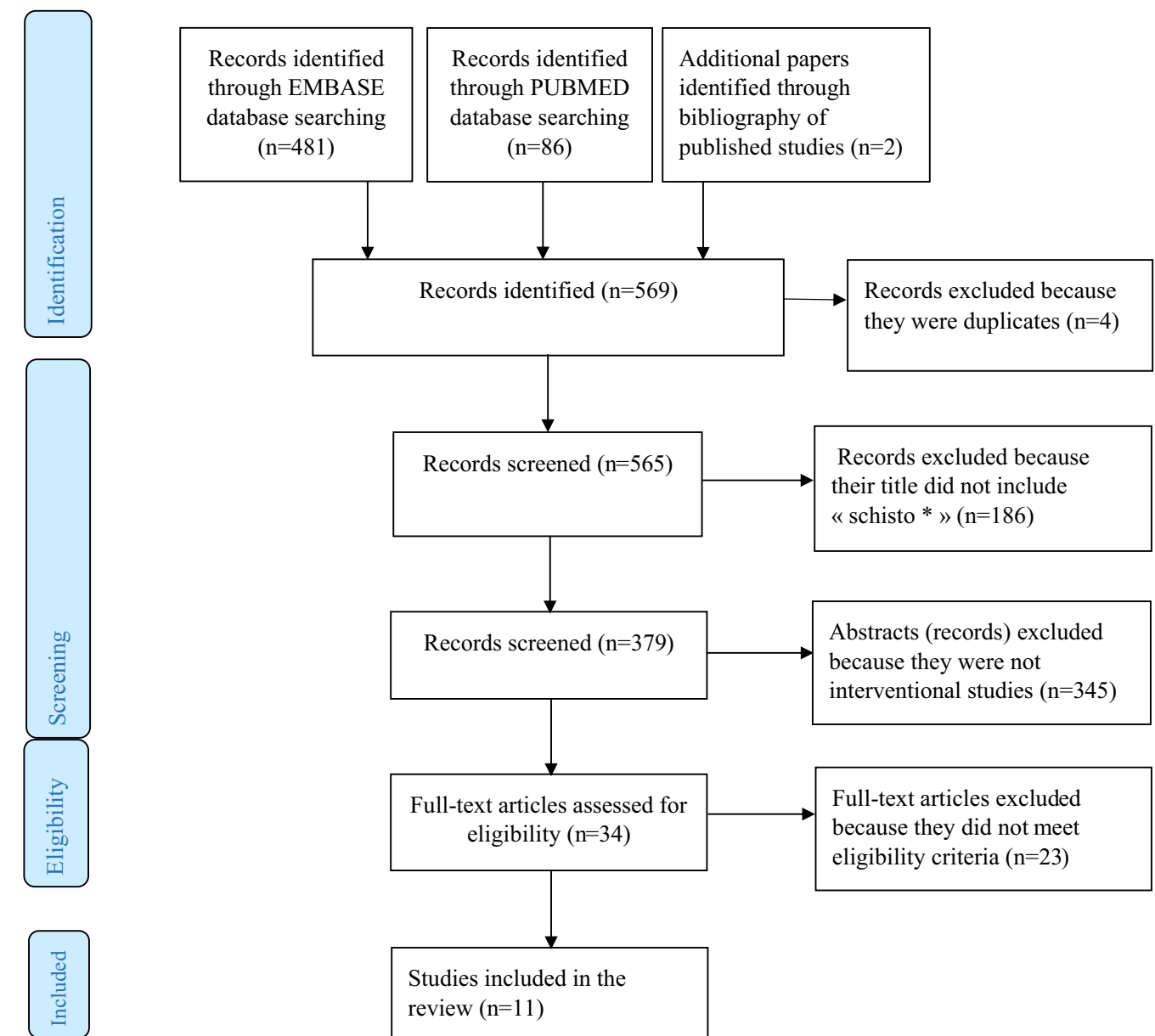

Fig. 1 Flow diagram. The different steps in the selection process of studies included in this review

schistosomiasis in the targeted population [23]. Table 1 shows in detail the different schistosomiasis control measures to be integrated within the $\mathrm{PHC}$, at the $\mathrm{HC}$ level and different related outcomes.

When both distal and intermediate outcomes were available, distal outcomes were analysed. When distal outcomes were missing, intermediate outcomes were taken into account. When available, results of statistical analysis were reported (comparison pre/post-intervention, $P<0.05)$. In their absence, quantitative pre- and post-intervention results were compared, and when postintervention results improved, it was concluded that the intervention had a positive effect, regardless of the improvement level. For post-intervention results related to KAP outcomes, more than $50 \%$ of the targeted subjects had to fulfil criteria that were considered as relevant (by the authors) to conclude that the intervention had a positive effect [24]. If quantitative results were not available, the qualitative appraisal of the authors of the respective studies was taken into account.

\section{Results}

In total, 569 titles were identified in all databases explored. After titles and abstracts were screened, 34 full texts were analysed, from which 11 studies were selected for the review (Fig. 1).

Out of these 11 studies, four were realised in West Africa (Senegal, Mali), three in Asia (Saudi Arabia), two in East Africa (Burundi), one in South America (Brazil) and one in Southern Africa (Botswana). Six papers were published between 1990 and 1995, three between 2000 and 2003 and two before 1990. The oldest publication was from 1988 and the most recent from 2003. All studies were before-and-after studies [22], without a control group. The main results are summarized in Table 2.

\section{Intervention effect analysis}

\section{Group one: $D / T$ and health education}

Group one consisted of three studies [25-27] which reported on intermediate outcomes only. In Senegal (2002) [27], the knowledge level of care providers in 


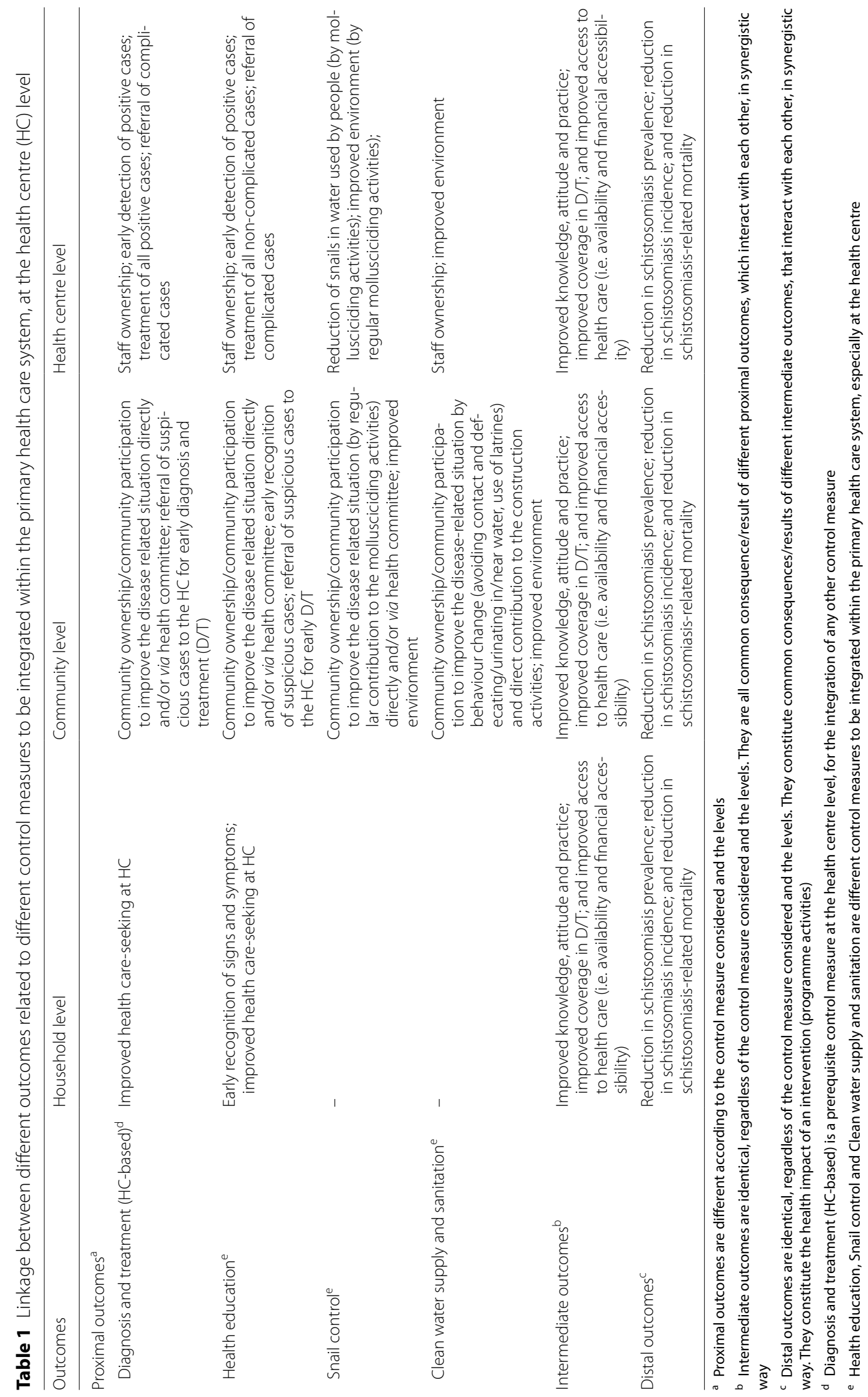




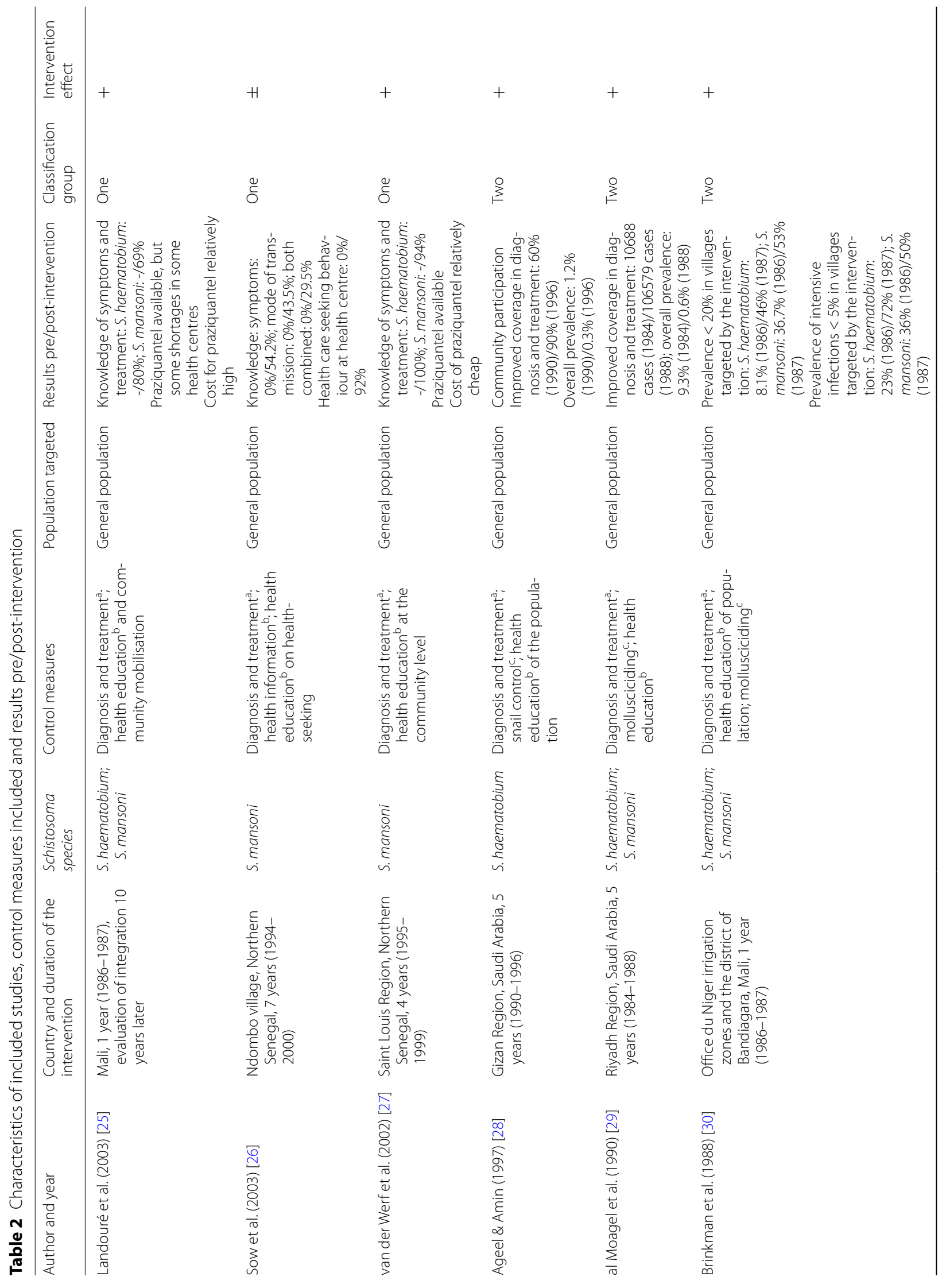


Bizimana et al. Parasites Vectors ～（2019) 12:393

Page 6 of 11

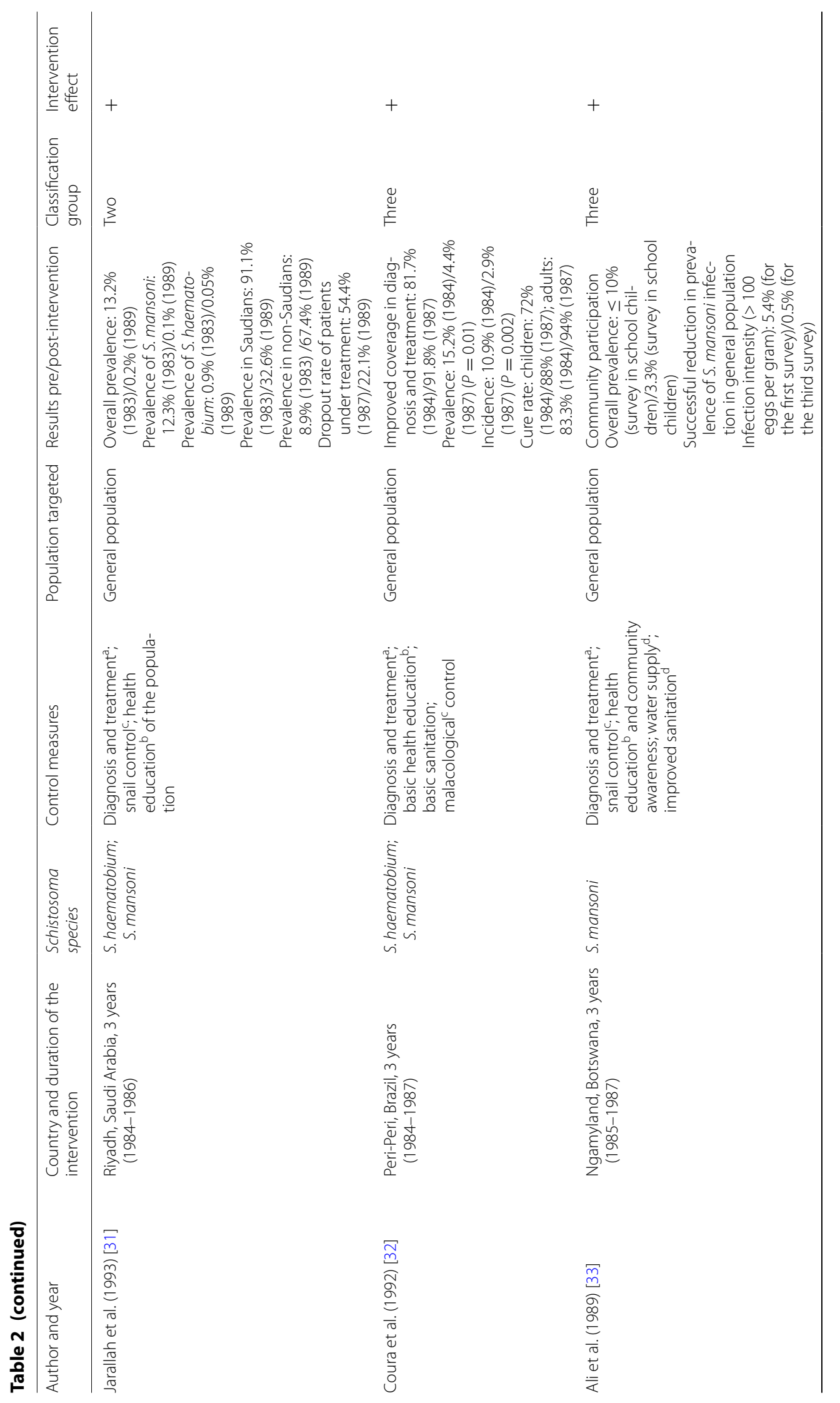


Bizimana et al. Parasites Vectors $\quad$ (2019) 12:393

Page 7 of 11

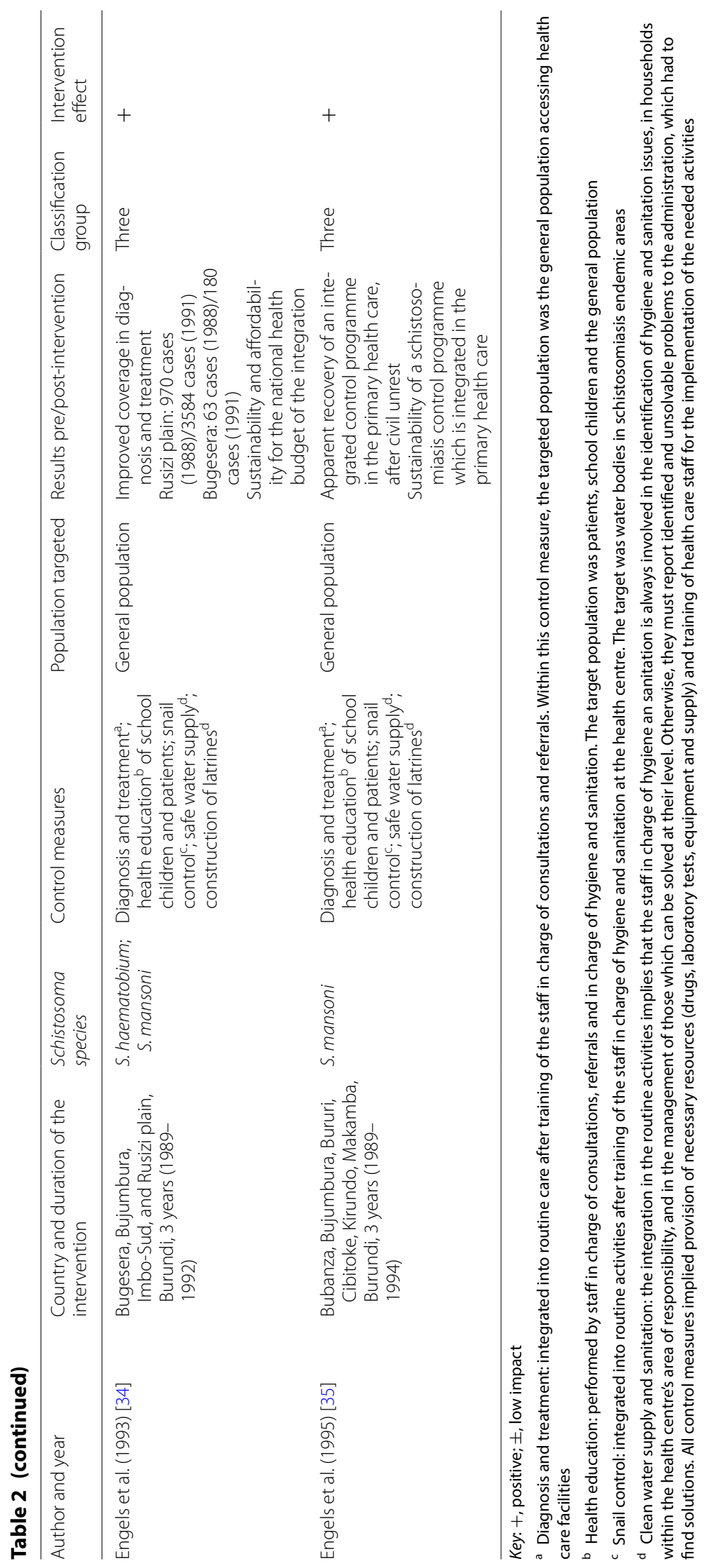


the HC post-intervention was much improved for both S. haematobium and S. mansoni. Results were similar but less impressive for the study in Mali (2003) [25]. Authors reported that PZQ was available and financially accessible in Senegal (2002) [27], while in Mali (2003) [25] some shortages were noted in some HC, with relatively high costs. Integration of $\mathrm{D} / \mathrm{T}$ and health education was considered to be successful in Senegal (2002) [27] and satisfactory in Mali (2003) [25]. Another study in Senegal (2003) [26] reported improvement in knowledge level of symptoms and in health care seeking behaviour at $\mathrm{HC}$, reaching 54.2 and $92 \%$ post-intervention, respectively. However, the knowledge level of modes of transmission, and both symptoms and modes of transmission at community level [26] was reported to be low.

\section{Group two: $D / T$, health education and control of snails}

Five studies belonged to group two. Four [28-31] of the five studies reported on prevalence only, while one [32] reported on prevalence and incidence. A significant decrease in prevalence $(P<0.05)$ and incidence $(P<0.05)$ was reported post-intervention in the study in Brazil (1992) [32]. The schistosomiasis prevalence decreased to less than one percent in three studies carried out in different regions in Saudi Arabia [28, 29, 31]. For a study in Mali (1988) [30], the outcome criterion was the number of villages with an infection prevalence of less than $20 \%$. The number of villages which fulfilled this condition increased from $8.1 \%$ to $46 \%$ for S. haematobium and from $36.7 \%$ to $53 \%$ for $S$. mansoni post-intervention.

\section{Group three: $D / T$, health education, control of snails, and clean water supply and sanitation}

Three studies were categorised in group three. One study in Botswana (1989) [33] reported on schistosomiasis prevalence and showed a decrease in prevalence postintervention. One study in Burundi (1993) [34] reported on $\mathrm{D} / \mathrm{T}$ coverage and affordability and showed an improved coverage. The authors reported that the available health infrastructure had allowed the control strategy to be integrated to a high degree into basic health services enabling it to be sustained and making it affordable for the national health budget. The third study was a report [35] on the number of cases of schistosomiasis detected in each quarter-year in basic health services in six schistosomiasis endemic provinces of Burundi. These were targeted by integration of schistosomiasis control in the PHC facilities, from 1989 onwards. According to the authors, results showed the sustainability of the PHC integrated schistosomiasis control programme.

\section{Discussion}

This review aimed to identify studies on the integration of schistosomiasis $\mathrm{D} / \mathrm{T}$ and other control measures in the PHC system, especially at the $\mathrm{HC}$ level, and to evaluate their effects.

We identified 11 studies which were all published before 2003. The lack of more recent studies could be explained by the fact that the emphasis of schistosomiasis control strategies has since then been on MDA [36], following the adoption of World Health Assembly (WHA) resolutions 54.19 (2001) and 65.21 (2012) that set control and elimination goals for schistosomiasis, respectively. Due to its cost-effectiveness and feasibility in low-resource settings, this strategy became the mainstay of schistosomiasis control, and other less straightforward strategies were given less attention. Since the global call for schistosomiasis elimination and the increasing evidence that MDA alone will not be sufficient for achieving this goal [18-20], the integration of schistosomiasis-related interventions into broader health systems has been put back on the agenda. Integrating schistosomiasis control should ensure that the delivery of health services meets the needs of those living with schistosomiasis. Moreover, it has the potential to accelerate progress towards Universal Health Coverage and to advance the Sustainable Development Goals [17].

For the studies in group one $(\mathrm{D} / \mathrm{T}$ and health education) all reporting on intermediate outcomes only, knowledge level of care providers, access to care and health care seeking behaviour of the community increased. However, no positive effect was observed on the knowledge level of symptoms and of modes of transmission at the community level.

The majority of studies from group two (with snail control as additional measure) and group three (with clean water supply and sanitation as additional measures) reporting on distal outcomes, showed a positive effect on schistosomiasis prevalence and incidence post-intervention, independent of the additional control measures implemented.

The positive effect on knowledge level of care providers following the training of the staff in charge of consultation and referrals on schistosomiasis, is supported by the literature [37-40]. The lack of a positive effect on knowledge at the community level may be explained by the complexity of public health interventions [40], such as health education, which may take a long time before achieving results.

The availability of resources for $\mathrm{D} / \mathrm{T}$, as well as financial accessibility for patients, are indispensable for improved access to care $[15,41]$. In Senegal, the retail selling price of drugs was determined by the local health committee, a group of representatives chosen 
from the population, which may have had a strong influence on the relatively low costs of PZQ and hence the access to treatment [26].

The positive effect on health care seeking practice at $\mathrm{HC}$ as observed in this review may be linked to the availability of means for the $\mathrm{D} / \mathrm{T}$ at the $\mathrm{HC}$, encouraging the population to visit a $\mathrm{HC}$ since they know they will be treated [42].

All studies included (i) D/T and (ii) health education. Some studies included additional control measures, such as control of snails (group two) or control of snails, and clean water and sanitation (group three). For all groups, distal outcomes were similar. One could conclude that clean water and sanitation did not bring any added value. However, it should be noted that the majority of the studies in group two were conducted in settings with a relatively high socioeconomic level $[28,29,31,32]$, which is likely to have contributed to the overall positive effect on schistosomiasis prevalence and incidence. Full socio-economic development remains essential for sustainable control and possibly elimination of schistosomiasis and other povertyrelated diseases.

Another important aspect is the political stability of the region in which the interventions are initiated [22]. Its absence can lead to the reduction and even total cessation of integrated control activities. However, Engels et al. [35] showed that integrated control at PHC, especially at the $\mathrm{HC}$ level, appears to be resilient, even after severe civil unrest of three years. In addition, a successful integration of schistosomiasis control measures at PHC level requires well functioning health systems [34, 43]. If the health system structure is already weak, it will only be further weakened, thereby not only hampering schistosomiasis control but also jeopardizing basic health care [11].

\section{Limitations}

This critical review has demonstrated the scarcity of studies showing the impact of integration of schistosomiasis control within the PHC structures. None of the identified studies was a randomized control trial, or had a control group, which could have provided more solid evidence on the impact of the studied interventions. Some studies had missing pre-intervention or incomplete data [25-27, 35] and some did not have distal outcomes [25$27,34,35]$. In addition, most studies had a limited duration and could therefore not provide sufficient evidence on the sustainability of the described interventions. There was also heterogeneity in study populations, methodologies and settings [22], which made comparison between studies difficult.

\section{Conclusions}

The results as described in these studies support the idea of a larger role for the PHC system in schistosomiasis prevention and control, and its integration within the routine activities of $\mathrm{PHC}$ facilities. However, more robust studies are needed, both qualitative and quantitative, especially in resource-limited regions, to conclusively demonstrate the effectiveness of integration of schistosomiasis control in the PHC system. The emphasis of current global schistosomiasis control strategies is on MDA with praziquantel, but this will likely not result in sustainable control, let alone elimination of schistosomiasis. Integration of $\mathrm{D} / \mathrm{T}$ and other schistosomiasis control measures into the PHC system offers clear opportunities to reduce the schistosomiasis burden in a sustainable way, thereby contributing to the Sustainable Development Goals.

\section{Abbreviations}

DALYs: disability-adjusted life years; HC: health centre; KAP: knowledge, attitude and practice; MDA: mass drug administration; PHC: primary health care; PZQ: praziquantel; WHO: World Health Organization.

\section{Acknowledgements}

The authors appreciate the Director of the Schistosomiasis Control Initiative, Professor Alan Fenwick, for supporting this project.

\section{Authors' contributions}

PB involved in the conception, acquisition and interpretation of data for the review and wrote the paper. KP, GO and JPVG made substantial contributions to the conception of the review, interpreted data and revised the manuscript critically. FN, AN and EM revised the manuscript. All authors read and approved the final manuscript.

\section{Funding}

The Schistosomiasis Control Initiative (SCI)/Imperial College and VLIR-UOS funded this study.

Availability of data and materials

Data supporting the conclusions of this article are included within the article.

Ethics approval and consent to participate

Not applicable.

Consent for publication

Not applicable.

\section{Competing interests}

The authors declare that they have no competing interests.

\section{Author details}

${ }^{1}$ Global Health Institute, Department of Epidemiology and Social Medicine, Faculty of Medicine and Health Sciences, University of Antwerp, Antwerp, Belgium. ${ }^{2}$ Département des Sciences de la Santé Publique, Direction de la Formation, Institut National de Santé Publique, Bujumbura, Burundi. ${ }^{3}$ Département de Médecine Communautaire, Faculté de Médecine de Bujumbura, Université du Burundi, Bujumbura, Burundi. ${ }^{4}$ Département des Sciences de la Santé Publique, Institut Universitaire des Sciences de la Santé et de Développement Communautaire, Bujumbura, Burundi. ${ }^{5}$ Centre for Neglected Tropical Diseases, Liverpool School of Tropical Medicine, Liverpool, UK.

${ }^{6}$ Département de Médecine Interne, Faculté de Médecine de Bujumbura, Université du Burundi, Bujumbura, Burundi. ${ }^{7}$ Programme National Intégré de Lutte contre les Maladies Tropicales Négligées et la Cécité, Département des programmes de santé, Ministère de la Santé Publique et de la Lutte contre le 
Sida, Bujumbura, Burundi. ${ }^{8}$ Medical Helminthology Unit, Department of Biomedical Sciences, Institute of Tropical Medicine, Antwerp, Belgium.

\section{Received: 19 December 2018 Accepted: 1 August 2019} Published online: 07 August 2019

\section{References}

1. Jamison DT, Mosley WH. Disease control priorities in developing countries: health policy responses to epidemiological change. Am J Public Health. 1991;81:15-22.

2. Hotez PJ, Molyneux DH, Fenwick A, Kumaresan J, Sachs SE, Sachs JD, et al. Control of neglected tropical diseases. N Engl J Med. 2007;357:1018-27.

3. Steinmann P, Keiser J, Bos R, Tanner M, Utzinger J. Schistosomiasis and water resources development: systematic review, meta-analysis, and estimates of people at risk. Lancet Infect Dis. 2006;6:411-25.

4. Chan MS. The global burden of intestinal nematode infections - fifty years on. Parasitol Today. 1997;13:438-43.

5. Savioli L, Albonico M, Engels D, Montresor A. Progress in the prevention and control of schistosomiasis and soil-transmitted helminthiasis. Parasitol Int. 2004;53:103-13.

6. van der Werf MJ, de Vlas SJ, Brooker S, Looman CW, Nagelkerke NJ, Habbema JD, et al. Quantification of clinical morbidity associated with schistosome infection in sub-Saharan Africa. Acta Trop. 2003;86:125-39.

7. Crompton DW, Nesheim MC. Nutritional impact of intestinal helminthiasis during the human life cycle. Annu Rev Nutr. 2002;22:35-59.

8. Hotez PJ, Bundy DAP, Beegle K, Brooker S, Drake L, de Silva N, et al. Helminth infections: Soil-transmitted helminth infections and schistosomiasis. In: Jamison DT, Breman JG, Measham AR, Alleyne G, Claeson M, Evans DB, Jha P, Mills A, Musgore P, editors. Disease control priorities in developing countries. 2nd ed. Oxford: Oxford University Press; 2006. p. 467-82.

9. Barakat R, El Masry AG, Farghaly A, el Morshidy HN, elSayed MK, Husein $\mathrm{MH}$, et al. Impact of population-based selective chemotherapy on prevalence and intensity of Schistosoma mansoni infections in the Nile Delta: Kafr El Sheikh. Trop Geogr Med. 1995;47:266-70.

10. el Malatawy A, el Habashy A, Lechine N, Dixon H, Davis A, Mott KE. Selective population chemotherapy among schoolchildren in Beheira governorate: the UNICEF/Arab Republic of Egypt/WHO Schistosomiasis Control Project. Bull World Health Organ. 1992;70:47-56.

11. Marchal B, Van DM, Pirard M, Cavalli A, Kegels G, Polman K. Neglected tropical disease (NTD) control in health systems: the interface between programmes and general health services. Acta Trop. 2011;120(Suppl. 1):S177-85

12. Ortu G, Williams O. Neglected tropical diseases: exploring long term practical approaches to achieve sustainable disease elimination and beyond. Infect Dis Poverty. 2017:6:147.

13. WHO. The control of schistosomiasis. World Health Organ Tech Rep Ser. 1993;830:1-86.

14. WHO. Schistosomiasis and soil-transmitted helminthiasis: prevention and control. World Health Organ Tech Rep Ser. 2004;912:29-55.

15. Gyapong JO, Gyapong M, Yellu N, Anakwah K, Amofah G, Bockarie M, et al. Integration of control of neglected tropical diseases into health-care systems: challenges and opportunities. Lancet. 2010;375:160-5.

16. Zhang Y, Macarthur C, Mubila L, Baker S. Control of neglected tropical diseases needs a long-term commitment. BMC Med. 2010:8:67.

17. WHO. Integrating neglected tropical diseases into global health and development: fourth WHO report on neglected tropical diseases. Geneva: World Health Organization; 2017.

18. Rollinson D, Knopp S, Levitz S, Stothard JR, Tchuem Tchuente LA, Garba A, et al. Time to set the agenda for schistosomiasis elimination. Acta Trop. 2013;128:423-40.

19. Singer $\mathrm{BH}$, de Castro MC. Bridges to sustainable tropical health. Proc Natl Acad Sci USA. 2007;104:16038-43.

20. Utzinger J, Raso G, Brooker S, de Savigny D, Tanner M, Ornbjerg N, et al. Schistosomiasis and neglected tropical diseases: towards integrated and sustainable control and a word of caution. Parasitology. 2009;136:1859-74.
21. Centers for Disease Control and Prevention. Introduction to program evaluation for public health programs: a self-study guide. Atlanta: Centers for Disease Control and Prevention; 2011.

22. Armstrong R, Waters E, Jackson N, Oliver S, Popay J, Shepherd J, et al. Guidelines for Systematic reviews of health promotion and public health interventions. Version 2. Melbourne: Melbourne University; 2007.

23. Lassi ZS, Salam RA, Das JK, Bhutta ZA. The conceptual framework and assessment methodology for the systematic reviews of communitybased interventions for the prevention and control of infectious diseases of poverty. Infect Dis Poverty. 2014;3:22.

24. Zaugg V, Savoldelli V, Sabatier B, Durieux P. Improving practice and organisation of care: methodology for systematic reviews. Sante Publique. 2014;26:655-67.

25. Landoure A, van der Werf MJ, Traore M, de Vlas SJ. Evaluation of case management in the integrated schistosomiasis-control programme in Mali. Ann Trop Med Parasitol. 2003;97:723-36.

26. Sow S, de Vlas SJ, Mbaye A, Polman K, Gryseels B. Low awareness of intestinal schistosomiasis in northern Senegal after 7 years of health education as part of intense control and research activities. Trop Med Int Health. 2003:8:744-9.

27. van der Werf MJ, Mbaye A, Sow S, Gryseels B, de Vlas SJ. Evaluation of staff performance and material resources for integrated schistosomiasis control in northern Senegal. Trop Med Int Health. 2002;7:70-9.

28. Ageel AR, Amin MA. Integration of schistosomiasis-control activities into the primary-health-care system in the Gizan region, Saudi Arabia. Ann Trop Med Parasitol. 1997;91:907-15.

29. Al Moagel M, Arfaa F, Abdulghani ME. The use of primary health care system in the control of schistosomiasis in the Riyadh Region of Saudi Arabia. Trop Med Parasitol. 1990;41:136-8.

30. Brinkmann UK, Werler C, Traore M, Korte R. The National Schistosomiasis Control Programme in Mali, objectives, organization, results. Trop Med Parasitol. 1988;39:157-61.

31. Jarallah JS, Al-Shammari SA, Khoja TA, Al-Sheikh M. Role of primary health care in the control of schistosomiasis. The experience in Riyadh. Saudi Arabia. Trop Geogr Med. 1993;45:297-300.

32. Coura FP, Rocha RS, de Lima e Costa MF, Katz N. A municipal level approach to the management of schistosomiasis control in Peri-Peri, MG, Brazil. Rev Inst Med Trop Sao Paulo. 1992;34:543-8.

33. Ali MI, Byskov J, Mokgweetsinyana SS, Sibiya J, Mott KE. Integration of control of schistosomiasis due to S. mansoni within primary health care in Ngamiland, Botswana. Trop Med Parasitol. 1989;40:195-200.

34. Engels D, Ndoricimpa J, Gryseels B. Schistosomiasis mansoni in Burundi: progress in its control since 1985. Bull World Health Organ. 1993;71:207-14.

35. Engels D, Sindayigaya B, Gryseels B. Sustainability of schistosomiasis case detection based on primary health care. Trans R Soc Trop Med Hyg. 1995:89:599.

36. WHO. First report of joint WHO Expert Committees on the prevention and control of schistosomiasis and soil-transmitted helminthiasis. World Health Organ Tech Rep Ser. 2002;912:1-57.

37. Celletti F, Wright A, Palen J, Frehywot S, Markus A, Greenberg A, et al. Can the deployment of community health workers for the delivery of HIV services represent an effective and sustainable response to health workforce shortages? Results of a multicountry study. AIDS. 2010;24(Suppl. 1):S45-57.

38. Lewin S, Lavis JN, Oxman AD, Bastias G, Chopra M, Ciapponi A, et al. Supporting the delivery of cost-effective interventions in primary health-care systems in low-income and middle-income countries: an overview of systematic reviews. Lancet. 2008;372:928-39.

39. Manafa O, McAuliffe E, Maseko F, Bowie C, MacLachlan M, Normand C. Retention of health workers in Malawi: perspectives of health workers and district management. Hum Resour Health. 2009;7:65.

40. Shediac-Rizkallah MC, Bone LR. Planning for the sustainability of community-based health programs: conceptual frameworks and future directions for research, practice and policy. Health Educ Res. 1998;13:87-108.

41. WHO. Declaration of Alma-Ata: International Conference on Primary Health Care. Kazakhstan, Alma-Ata, 12 Sept 1978. https://www.who.int/ topics/primary_health_care/alma_ata_declaration/fr/. Accessed 10 Dec 2018. 
42. Bizimana P, Polman K, Van Geertruyden JP, Nsabiyumva F, Ngenzebuhoro C, Muhimpundu E, et al. Capacity gaps in health facilities for case management of intestinal schistosomiasis and soil-transmitted helminthiasis in Burundi. Infect Dis Poverty. 2018;7:66.

43. Salam RA, Maredia H, Das JK, Lassi ZS, Bhutta ZA. Community-based interventions for the prevention and control of helmintic neglected tropical diseases. Infect Dis Poverty. 2014;3:23.

\section{Publisher's Note}

Springer Nature remains neutral with regard to jurisdictional claims in published maps and institutional affiliations.
Ready to submit your research? Choose BMC and benefit from:

- fast, convenient online submission

- thorough peer review by experienced researchers in your field

- rapid publication on acceptance

- support for research data, including large and complex data types

- gold Open Access which fosters wider collaboration and increased citations

- maximum visibility for your research: over 100M website views per year

At BMC, research is always in progress.

Learn more biomedcentral.com/submissions 